\title{
Fusarium oxysporum Protects Douglas-fir (Pseudotsuga menziesii) Seedlings from Root Disease Caused by Fusarium commune
}

\author{
R. Kasten Dumroese ${ }^{1}$, Mee-Sook Kim ${ }^{2 *}$ and Robert L. James ${ }^{3}$ \\ ${ }^{1}$ USDA Forest Service, Rocky Mountain Research Station, Moscow, ID 83843, USA \\ ${ }^{2}$ Department of Forestry, Environment, and Systems, Kookmin University, Seoul 136-702, Korea \\ ${ }^{3}$ USDA Forest Service, Forest Health Protection, Coeur d'Alene, ID 83815, USA
}

(Received on August 29, 2011; Revised on January 30, 2012; Accepted on January 30, 2012)

\begin{abstract}
Fusarium root disease can be a serious problem in forest and conservation nurseries in the western United States. Fusarium inoculum is commonly found in most container and bareroot nurseries on healthy and diseased seedlings, in nursery soils, and on conifer seeds. Fusarium spp. within the $F$. oxysporum species complex have been recognized as pathogens for more than a century, but attempts to distinguish virulence by correlating morphological characteristics with results of pathogenicity tests were unsuccessful. Recent molecular characterization and pathogenicity tests, however, revealed that selected isolates of $F$. oxysporum are benign on Douglas-fir (Pseudotsuga menziesii) seedlings. Other morphologically indistinguishable isolates, which can be virulent, were identified as $\boldsymbol{F}$. commune, a recently described species. In a replicated greenhouse study, inoculating Douglas-fir seedlings with one isolate of $F$. oxysporum prevented expression of disease caused by a virulent isolate of $\boldsymbol{F}$. commune. Moreover, seedling survival and growth was unaffected by the presence of the F. oxysporum isolate, and this isolate yielded better biological control than a commercial formulation of Bacillus subtilis. These results demonstrate that an isolate of nonpathogenic $F$. oxysporum can effectively reduce Fusarium root disease of Douglas-fir caused by $F$. commune under nursery settings, and this biological control approach has potential for further development.
\end{abstract}

Keywords : biological control, Fusarium commune, Fusarium oxysporum, nursery management, root disease, Pseudotsuga menziesii

The association of Fusarium spp., particularly those in the F. oxysporum Schlechtend.:Fr. taxon, with damping-off and root disease in conifer reforestation nurseries of the western United States has been recognized for nearly a century (Spaulding, 1914). These fungi are important pathogens in

\footnotetext{
*Corresponding author.

Phone) +82-2-910-4733, FAX) +82-2-910-4809

E-mail)mkim@kookmin.ac.kr
}

bareroot and container nurseries (Bloomberg, 1971; Dumroese and James, 2005), affecting a variety of plant species including conifers (Kim et al., 2012). Foliar chlorosis, necrosis, and wilting can be above-ground symptoms of this root disease (Dumroese and James, 2005). Although the epidemiology has been discerned (James et al., 1987) and integrated pest management techniques recommended (Dumroese et al., 2002), Fusarium spp. continue to cause damage to seedling crops, especially Douglas-fir (Pseudotsuga menziesii (Mirbel) Franco) and western white pine (Pinus monticola Dougl. ex D. Don). Chemical pesticides are generally in effective, especially late in the crop production cycle. Known potential biological control agents are also often ineffective, likely because they were developed for use in agronomic, rather than forestry systems (Fravel et al., 2003).

Efforts to improve disease control have been hampered because of an inability to correlate $F$. oxysporum populations with subsequent disease potential (Stewart et al., 2012). Morphologically similar isolates of $F$. oxysporum can exhibit wide ecological variability (Gordon and Martyn, 1997). For example, isolates classified as $F$. oxysporum based on morphology were found to have a wide range of virulence on Douglas-fir (Stewart et al., 2006). Recent molecular studies using amplified fragment length polymorphism (AFLP) and DNA sequencing confirmed that selected nonvirulent Fusarium were $F$. oxysporum; whereas, virulent isolates were identified as $F$. commune, a recently described species (Skovgaard et al., 2003; Stewart et al., 2006).

Fungi classified as $F$. commune and $F$. oxysporum are morphologically indistinguishable, but genetically very distinct (Stewart et al., 2006), showing disparate levels of virulence on Douglas-fir seedlings (Stewart et al., 2012). Both fungi are apparently well-adapted to forest nursery environments. Previous studies using crops other than Douglas-fir in nurseries have shown that non-pathogenic $F$. oxysporum can prevent disease by pathogenic $F$. oxysporum (Fuchs et al., 1999; Fravel and Larkin, 2002; HuertasGonzalez et al., 1999; Larkin and Fravel, 2002; Shishido et 
al., 2005). We therefore hypothesized that some nonpathogenic isolates of $F$. oxysporum may have the potential to protect conifer seedlings from virulent isolates of $F$. commune. Our study objectives were to determine if 1) non-pathogenic $F$. oxysporum could infect Douglas-fir seedlings without causing adverse effects, such as reducing growth; and 2) non-pathogenic $F$. oxysporum can potentially protect Douglas-fir seedlings against a highly virulent isolate of $F$. commune. We believe this paper is the first to describe biological control of $F$. commune with $F$. oxysporum, and the first to employ non-pathogenic isolates from forest and conservation nurseries in the western United States against a common pathogen in those same systems.

Based on previous (Stewart et al., 2006) and subsequent (unpublished) AFLP and DNA sequencing results, we selected three $F$. oxysporum isolates (Fo-Q12, Fo-Q76, and Fo-N16; hereafter Q12, Q76, and N16) from diverse phylogenetic clades and a $\mathrm{F}$. commune isolate (Fc-H14; hereafter H14). Fusarium oxysporum isolates Q12, Q76, and N16 were initially obtained from the roots of a diseased western white pine seedling, an asymptomatic western white pine seedling, and a diseased Douglas-fir seedling, respectively. The highly virulent isolate (H14) was obtained from a diseased Douglas-fir seedling and was originally identified as $F$. oxysporum based on morphology as described by Nelson et al. (1983). Although H14 was previously used in pathogenicity tests, it was only recently identified as $F$. commune based on molecular genetic analyses (Stewart et al., 2006). Following isolation, all isolates were maintained on carnation leaves in sterile water (Fisher et al., 1982). We evaluated pathogenicity of all isolates using traditional Koch's postulates with Douglas-fir seedlings as hosts. These tests revealed that the $3 F$. oxysporum isolates were non-pathogenic and the $F$. commune isolate was highly virulent (data not included).

Inoculum for pathogenicity testing was prepared as described by Miles and Wilcoxson (1984) because similar inoculum was effective in previous pathogenicity tests on conifer seedlings (James et al., 1989). Perlite, an inert, inorganic, siliceous rock of volcanic origin commonly used in soilless planting media in conifer container nurseries, was the matrix for fungal growth. Inoculum consisted of $150 \mathrm{~g}$ of yellow cornmeal moistened with $300 \mathrm{ml}$ warm $1 \%$ potato dextrose agar (PDA), mixed with $75 \mathrm{~g}$ of perlite. This mixture was autoclaved for $60 \mathrm{~min}$ at $121^{\circ} \mathrm{C}(1.3 \mathrm{~kg}$ $\mathrm{cm}^{-2}$ ). After cooling, the perlite-cornmeal mixture was inoculated with mycelium from 14-day-old cultures of each Fusarium isolate grown on PDA. Inoculum was incubated in the dark at about $24^{\circ} \mathrm{C}$ for 20 to 24 days. Following incubation, the inoculum was air dried within a cabinet for at least 3 days and kept refrigerated in plastic bags until needed. Similar inoculum was previously stored this way for several months without loss of viability (James et al., 1989).

Our experiment employed a 6 inoculation treatments (described below) $\times 2$ levels of $F$. commune isolate H14 (present or absent) $\times 3$ replications $\times 10$ seedlings factorial design. The 6 inoculation treatments were as follows. Treatment 1 was the control: non-inoculated Pro-Mix ${ }^{\circledR}$ HP [ca $70 \%$ (v:v) Sphagnum peat moss and ca 30\% (v:v) horticulture coarse-grade perlite; Premier Horticulture, Quakertown, Pennsylvania, USA]. Treatment 2 was Pro-Mix ${ }^{\circledR}$ BX, the same medium as Pro-Mix ${ }^{\circledR}$ HP but commercially inoculated with the proprietary biofungicide Subtilex ${ }^{\circledR}$, a strain of Bacillus subtilis (GB03). Treatments 3 through 5 each included inoculum of one F. oxysporum isolate (Q12, Q76, or N16, respectively) mixed (1:50, w:w) with the same ProMix $^{\circledR}$ HP used in Treatment 1. Both Pro-Mix ${ }^{\circledR}$ media had a moisture content of $42 \%$ when inoculum was added. Treatment 6 was a combination of all three $F$. oxysporum isolates (Q12, Q76, and N16); inoculum for each isolate was added to Pro-Mix ${ }^{\circledR} \mathrm{HP}$ at a rate of 1:16 (w:w). For each inoculation treatment $\times F$. commune level $\times$ replication combination we filled 10 individual containers (Ray Leach Conetainers $^{\mathrm{TM}}$, Stuewe \& Sons, Inc., Tangent, OR, USA; 2.5-cm diameter, 16-cm length, 66-ml volume, 1076 containers $\mathrm{m}^{-2}$ ) often used to grow conifer seedlings (360 containers total). A subsample of each potting medium was collected for assay of potentially pathogenic fungi. Once filled in mid April, containers were sown with 3 seeds each of interior Douglas-fir (P. menziesii var. glauca Beissn.) from the Flathead National Forest in western Montana USA (Hungry Horse Ranger District; $1675 \mathrm{~m}$ elevation) that had been stratified for 28 days. Seeds were covered with about $1 \mathrm{~cm}$ of fine rock mulch (1.2- to 4.8-mm particles; Target ${ }^{\mathbb{R}}$ Forestry Nursery Grit, Target Products Ltd., Burnaby, British Columbia, Canada) and placed on metal tables inside a fully-controlled greenhouse. Target greenhouse temperatures and photoperiod followed the recommendations of Wenny and Dumroese (1992). Most seeds germinated between 7 and 14 days after sowing; emerged seedlings were thinned to a single seedling per container. Beginning 3 weeks after sowing and continuing throughout the experiment, each inoculation treatment $\times F$. commune level $\times$ replication combination was fertigated when container weights were $85 \%$ of field capacity (Landis et al., 1989). The fertigation was performed with a soluble fertilizer containing the following (mg/L): $150 \mathrm{~N}$ (100 as $\mathrm{NO}_{3}^{-}$and 50 as $\left.\mathrm{NH}_{4}{ }^{+}\right), 50$ P, $170 \mathrm{~K}, 45 \mathrm{Ca}, 20 \mathrm{Mg}, 62 \mathrm{~S}, 20 \mathrm{Fe}$, and 15 S.T.E.M. ${ }^{\circledR}$ (micronutrients; The Scotts Co., Marysville, Ohio). Containers were systematically rearranged at regular intervals to minimize microclimate variation.

Three months after sowing (mid July), we carefully 
removed seedlings from their containers and gently shook the media from roots. All seedlings in the "absent" $F$. commune $\mathrm{H} 14$ treatments were transplanted into noninoculated Pro-Mix ${ }^{\circledR}$ HP (180 total), whereas seedlings in the "present" F. commune H14 treatments (180 total) were transplanted into Pro-Mix ${ }^{\circledR}$ HP inoculated (1:50, w:w) with the highly virulent $F$. commune $\mathrm{H} 14$ as described above. A subsample of the Pro-Mix ${ }^{\circledR}$-inoculum mixture was collected to assay for viable $F$. commune.

Four weeks after transplanting (mid August), seedlings in each inoculation treatment $\times F$. commune level $\times$ replication were rated for their severity of foliar symptoms using a 1 to 5 system as described in James et al. (1989). In this experiment, however, seedlings fell into only three of the classifications. Seedlings with a rating of 1 were asymptomatic, lacking foliar chlorosis or necrosis; seedlings with a rating of 3 had evidence of necrosis on $<50 \%$ of their foliage. Dead seedlings received a rating of 5 . All seedlings were carefully removed from their containers and their roots were gently washed to remove adhering potting medium. Samples of the potting media from control seedlings (no $F$. oxysporum or Bacillus) later exposed to F. commune were retained for assay of the pathogen. Healthy seedlings were measured for height (root collar to tip of terminal bud) and root collar diameter. For all seedlings (diseased and healthy), 10 lateral roots were randomly selected and 2- to 3-mmlong tips were aseptically served and incubated on Komada's medium, a selective medium for Fusarium spp., especially F. oxysporum (Komada, 1975). Remaining roots and shoots from healthy appearing seedlings were dried at $60{ }^{\circ} \mathrm{C}$ until constant weight to determine biomass. The peatbased growing medium was assayed using a standard soildilution technique (James et al., 1996). After a 7- to 10-day incubation, fungal isolates from roots and media were observed; the most common colonies were selected from each treatment combination for DNA extraction and sequencing as described in Stewart et al. (2006) to confirm that the isolates were the same that were inoculated onto seedlings.

Our study design tested six inoculation treatments (control; F. oxysporum Q12, Q76, and N16; a combination of all 3 isolates; and Bacillus subtillus GB03) with either the presence or absence of the highly virulent isolate (F. commune H14). After confirming homogeneity of variance, we used separate ANOVAs (Statistical Analysis System Institute, Gary, NC, USA) to compare height, root collar diameter, and biomass of apparently healthy seedlings among potential biological control treatments with and without the presence of the highly virulent isolate. When the $F$-tests were significant at $P=0.05$, we used least squared means (lsmeans) to separate means. For survival of seedlings after exposure to the highly virulent isolate, we analyzed data with a Chi-square test and calculated the $P$ value using the Monte Carlo estimation (Agresti et al., 1979).

Seedlings inoculated with only F. oxysporum (Q12, Q76, N16, or the combination) were found to have roots colonized with $F$. oxysporum, whereas seedlings inoculated with only $\mathrm{H} 14$ were found to be colonized by $F$. commune based on DNA sequences of the elongation factor $1-\alpha$ and mitochondrial small subunit rDNA (data not shown). Similarly, after inoculation with both $F$. oxysporum and $F$. commune, subsequent asymptomatic seedlings yielded both species.

We detected no significant treatment differences in height, root-collar diameter, or biomass of asymptomatic seedlings when inoculated with the potential biological controls, even when subsequently exposed to $F$. commune (Table 1 ). In the absence of $F$. commune, no seedlings died in the control or had necrotic foliage when exposed to any of the F. oxysporum isolates or Bacillus subtilis GB03. Seedling survival was significantly different, however, after control and biocontrol-inoculated seedlings were exposed to $F$. commune $(X=24.3770 ; P=0.0050)$. Seedlings initially inoculated

Table 1. Means ( \pm S.E.) of morphological characteristics for Douglas-fir seedlings inoculated with potential biological controls and subsequently challenged with Fusarium commune

\begin{tabular}{|c|c|c|c|c|c|c|c|c|}
\hline \multirow[b]{2}{*}{ Treatments } & \multirow[b]{2}{*}{$\mathrm{n}$} & \multirow[b]{2}{*}{$\begin{array}{l}\text { Height } \\
(\mathrm{cm})\end{array}$} & \multirow[b]{2}{*}{$\begin{array}{c}\text { Root-collar } \\
\text { diameter }(\mathrm{mm})\end{array}$} & \multirow[b]{2}{*}{$\begin{array}{l}\text { Biomass } \\
(\mathrm{g})\end{array}$} & \multicolumn{4}{|c|}{ Challenged with Fusarium commune Fc-H14 ${ }^{\mathrm{a}}$} \\
\hline & & & & & $\mathrm{n}$ & $\begin{array}{c}\text { Height } \\
(\mathrm{cm})\end{array}$ & $\begin{array}{c}\text { Root-collar } \\
\text { diameter }(\mathrm{mm})\end{array}$ & $\begin{array}{c}\text { Biomass } \\
(\mathrm{g})\end{array}$ \\
\hline Control & 30 & $9.0(0.2)$ & $1.39(0.03)$ & $0.29(0.01)$ & 17 & $9.3(0.3)$ & $1.52(0.04)$ & $0.30(0.02)$ \\
\hline Bacillus subtillus GB03 & 30 & $8.7(0.2)$ & $1.41(0.03)$ & $0.28(0.01)$ & 16 & $8.0(0.3)$ & $1.38(0.04)$ & $0.24(0.02)$ \\
\hline Fusarium oxysporum Fo-Q12 & 30 & $8.5(0.2)$ & $1.45(0.03)$ & $0.28(0.01)$ & 30 & $8.6(0.2)$ & $1.51(0.03)$ & $0.29(0.01)$ \\
\hline F. oxysporum Fo-Q76 & 30 & $8.0(0.2)$ & $1.42(0.03)$ & $0.27(0.01)$ & 20 & $8.7(0.3)$ & $1.44(0.04)$ & $0.28(0.01)$ \\
\hline F. oxysporum Fo-N16 & 30 & $8.2(0.2)$ & $1.38(0.03)$ & $0.27(0.01)$ & 18 & $8.2(0.3)$ & $1.43(0.04)$ & $0.26(0.02)$ \\
\hline $\begin{array}{l}\text { F. oxysporum combination } \\
\text { (Fo-Q12 + Fo-Q76 + Fo-N16) }\end{array}$ & 30 & $8.6(0.2)$ & $1.43(0.03)$ & $0.28(0.01)$ & 25 & $8.2(0.3)$ & $1.44(0.03)$ & $0.27(0.01)$ \\
\hline$P$ value & & 0.0602 & 0.0530 & 0.7889 & & 0.0899 & 0.0737 & 0.0804 \\
\hline
\end{tabular}

${ }^{a}$ Only asymptomatic seedlings evaluated. 


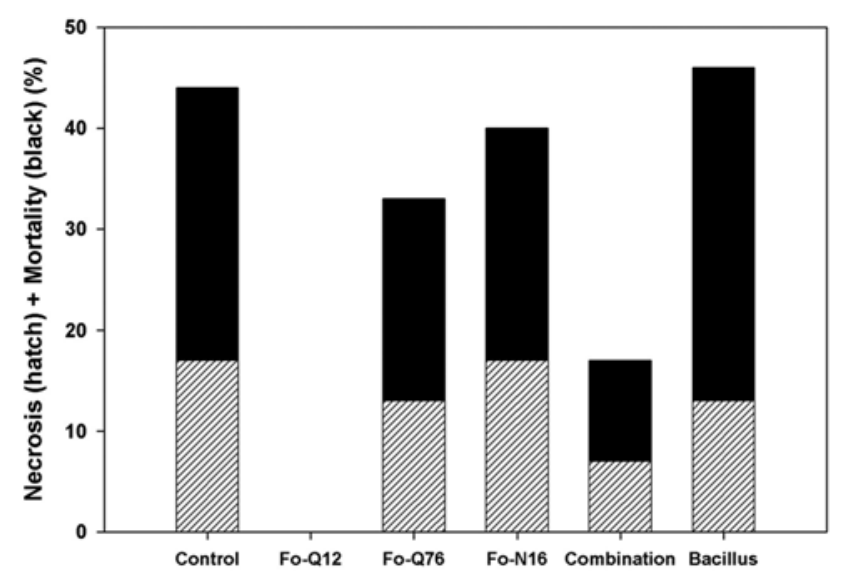

Fig. 1. Seedlings were grown 3 months in the presence of Fusarium oxysporum isolates Fo-Q12, Fo-Q76, and Fo-N16; a combination of all 3 isolates; Bacillus subtillus GB03; or a noninoculated control. The hatched portion of the bars shows the percentage of seedlings that developed necrotic needles (but $<50 \%$ of foliage was affected; classification 3 as described in James et al. (1989)) after being transplanted into medium containing Fusarium commune Fc-H14; whereas the black portion indicates the percentage that died. Fusarium oxysporum Fo-Q12 had significantly less necrosis (zero) and mortality (zero) than the other treatments, which were similar in response.

with $F$. oxysporum Q12 and subsequently exposed to $F$. commune exhibited no necrosis or mortality (Fig. 1). No significant differences were observed, however, among the other treatments exposed to $F$. commune with respect to incidence of necrotic foliage or mortality.

In this study, Bacillus subtilis GB03 was ineffective in protecting Douglas-fir from a pathogenic isolate of $F$. commune. We have previously found that a commercially available isolate of the biocontrol fungus Gliocladium virens, marketed to protect seedlings against Fusarium root disease, was also ineffective (Dumroese et al., 1996). Our experience is that application of potential biological control fungi developed from agronomic environments for specific crops show little (Dumroese et al., 1998) to modest (Mousseaux et al., 1998) benefit with conifer seedlings. A isolate of F. oxysporum (Fo47) has been an effective biological control against pathogenic $F$. oxysporum on many species (e.g., Blok et al., 1997; Fuchs et al., 1997) including some tree seedlings (Salerno et al., 2000). In limited laboratory tests, however, this isolate, which is closely related to our $F$. oxysporum isolates, did not protect young Douglas-fir germinants from pathogenic Fusarium spp. (James, 2002).

The non-pathogenic F. oxysporum Q12 provided excellent protection of Douglas-fir seedlings against the virulent $F$. commune $\mathrm{H} 14$ without adversely affecting seedling growth. The biocontol efficacy of $F$. oxysporum Q12 is perhaps attributable to its collection from a specialized nursery environment. Cropping system adaptation associated with increased biocontrol efficacy has been previously described for Fusarium (Fravel et al., 2003). Our ability to routinely isolate both $F$. oxysporum and $F$. commune from Douglasfir roots indicates that these species likely occupy similar rhizosphere niches and may compete for available nutrients and/or the same root infection sites. If so, prior inoculation of Douglas-fir seedlings with certain non-pathogenic $F$. oxysporum strains may have restricted $F$. commune access to roots (e.g., Alabouvette et al., 1993; Fuchs et al., 1999). Induced systematic resistance has been reported in Fusarium (Fuchs et al., 1997; Larkin and Fravel, 1999; Mandeel and Baker, 1991). Perhaps, F. oxysporum Q12 is able to induce systematic resistance more effectively than either $F$. oxysporum Q76 or N16. Moreover, this may be why F. oxysporum Q12 was an effective biocontrol agent when applied to seedlings before exposure to $F$. commune at the same concentration (i.e., 1:1). Other studies indicated that much higher concentrations of the biocontrol agent (e.g., 10:1 to 100:1 for Fo47) must be present to effectively restrict disease when plants are exposed to the pathogen and biocontrol agent simultaneously (Alabouvette et al., 1993; Bolwerk et al., 2005; Larkin and Fravel, 1999). Biocontrol activities can be attributed to diverse factors, such as antibiosis, competition, induced host resistance, interactions with other microbes, or other mechanisms (Fravel et al., 2003; Hadelsman and Stabb, 1996). Further studies are needed to determine the mode of action for the biocontrol activity of $F$. oxysporum Q12 against highly virulent $F$. commune H14.

Although we successfully controlled root disease caused by $F$. commune by prior inoculation with a non-pathogenic isolate of $F$. oxysporum, only one virulent isolate was tested and only one non-pathogenic isolate offered control. Clearly, additional work is needed to determine the scope of efficacy, particularly with additional conifer species. Testing additional non-pathogenic $F$. oxysporum isolates, which are genetically similar to Q12, may reveal other isolates with biocontrol potential. Additionally, the efficacy of $F$. oxysporum $\mathrm{Q} 12$ against diverse $F$. commune isolates also warrants testing.

\section{Acknowledgments}

This work was supported by the U.S. Department of Agriculture Forest Service, National Center for Reforestation, Nurseries, and Genetic Resources; Rocky Mountain Research Station; Research Joint Venture Agreement (07-JV-11221662078); Region 1 Forest Health Protection (Coeur d'Alene Field Office); and Research Program 2012 of Kookmin University in Korea. We thank J.R. Pinto for his assistance in the greenhouse and R. Wallace for statistical analysis. 


\section{References}

Agresti, A., Wackerly, D. and Boyett, J. M. 1979. Exact conditional tests for cross-classifications: approximation of attained significance levels. Psychometrika 44:75-83.

Alabouvette, C., Lemanceau, P. and Steinberg, C. 1993. Recent advances in biological control of Fusarium wilts. Pestic. Sci. 37:365-373.

Blok, W. J., Zwankhuizen, M. J. and Bollen, G. J. 1997. Biological control of Fusarium oxysporum f.sp. asparagi by applying non-pathogenic isolates of F. oxysporum. Biocontrol Sci. Techn. 7:525-541.

Bloomberg, W. J. 1971. Diseases of Douglas-fir seedlings caused by Fusarium oxysporum. Phytopathology 61:467-470.

Bolwerk, A., Lagopodi, A. L., Lugtenberg, B. J. J. and Bloemberg, G. V. 2005. Visualization of interactions between a pathogenic and a beneficial Fusarium strain during biocontrol of tomato foot and root rot. Mol. Plant-Microbe Interact. 18:710-721.

Dumroese, R. K. and James, R. L. 2005. Root diseases in bareroot and container nurseries of the Pacific Northwest: epidemiology, management, and effects on outplanting performance. New Forest. 30:185-202.

Dumroese, R. K., James, R. L. and Wenny, D. L. 1996. Gliocladium virens in an alginate prill ineffective as a biological control of Fusarium root disease in container-grown Douglas-fir. New Forest. 12:113-124.

Dumroese, R. K., James, R. L. and Wenny, D. L. 1998. Interactions between Streptomyces griseoviridis, Fusarium root disease, and Douglas-fir seedlings. New Forest. 15:181-191.

Dumroese, R. K., James, R. L. and Wenny, D. L. 2002. Hot water and copper coatings in reused containers decrease inoculum of Fusarium and Cylindrocarpon and increase Douglas-fir seedling growth. HortScience 37:943-947.

Fisher, N. L., Burgess, L. W., Toussoun, T. A. and Nelson, P. E. 1982. Carnation leaves as a substrate and for preserving cultures of Fusarium species. Phytopathology 72:151-153.

Fravel, D. R. and Larkin, R. P. 2002. Reduction of Fusarium wilt of hydroponically grown basil by Fusarium oxysporum strain CS-20. Crop Prot. 21:539-543.

Fravel, D.R., Olivain, C., and Alabouvette, C. 2003. Fusarium oxysporum and its biocontrol. New Phytol. 157:493-502.

Fuchs, J.-G., Moënne-Loccoz, Y. and Défago, G. 1997. Nonpathogenic Fusarium oxysporum strain Fo47 induces resistance to Fusarium wilt in tomato. Plant Dis. 81:492-496.

Fuchs, J.-G., Moënne-Loccoz, Y. and Défago, G. 1999. Ability of nonpathogenic Fusarium oxysporum Fo47 to protect tomato against Fusarium wilt. Biol. Control 14:105-110.

Gordon, T. R. and Martyn, R. D. 1997. The evolutionary biology of Fusarium oxysporum. Annu. Rev. Phytopathol. 35:111-128.

Handelsman, J. and Stabb, E. V. 1996. Biocontrol of soilborne plant pathogens. Plant Cell 8:1855-1869.

Huertas-Gonzalez, M. D., Ruiz-Roldan, M. C., De Pietro, A. and Roncero, M. I. G. 1999. Cross protection provides evidence for race-specific avirulence factors in Fusarium oxysporum. Physiol. Mol. Plant Pathol. 54:63-72.
James, R. L. 2002. Biological control of Fusarium oxysporum and Fusarium proliferatum on young Douglas-fir seedlings by a nonpathogenic strain of Fusarium oxysporum. United States Department of Agriculture, Forest Service, Northern Region, Forest Health Protection. Report 02-2, 14 p.

James, R. L., Dumroese, R. K., Wenny, D. L., Myers, J. F. and Gilligan, C. J. 1987. Epidemiology of Fusarium on containerized Douglas-fir seedlings. (1) Seed and seedling infection, symptom production, and disease progression. United States Department of Agriculture, Forest Service, Timber, Cooperative Forestry and Pest Management, Northern Region. Report 87-13, 22 p.

James, R. L., Dumroese, R. K., Gilligan, C. J. and Wenny, D. L. 1989. Pathogenicity of Fusarium isolates form Douglas-fir seed and container-grown seedlings. University of Idaho, Idaho Forest, Wildlife and Range Experiment Station. Bulletin Number 52, $10 \mathrm{p}$.

James, R. L., Page-Dumroese, D. S., Kimball, S. K. and Omi, S. 1996. Effects of Brassica cover crop, organic amendment, fallowing, and soil fumigation on production of bareroot Douglas-fir seedlings - USDA Forest Service Nursery, Coeur d'Alene, Idaho. United States Department of Agriculture, Forest Service, Northern Region, Forest Health Protection. Report 96-6, $10 \mathrm{p}$.

Kim, M.-S., Stewart, J. E., Dumroese, R. K. and Klopfenstein, N. B. 2012. Occurrence of the root rot pathogen, Fusarium commune, in forest nuseries of the midwestern and western United States. J. Phytopathol. 160:112-114.

Komada, H. 1975. Development of a selective medium for quantitative isolation of Fusarium oxysporum from natural soil. Rev. Plant Protect. Res. 8:114-125.

Landis, T. D., Tinus, R. W., McDonald, S. E. and Barnett, J. P. 1989. Seedling Nutrition and Irrigation, Volume 4, The Container Tree Nursery Manual. United States Department of Agriculture, Forest Service. Agriculture Handbook 674, 119 p.

Larkin, R. P. and Fravel, D. R. 1999. Mechanisms of action and dose-response relationships governing biological control of Fusarium wilt of tomato by nonpathogenic Fusarium spp. Phytopathology 89:1152-1161.

Larkin, R. P. and Fravel, D. R. 2002. Effects of varying environmental conditions on biological control of Fusarium wilt of tomato by nonpathogenic Fusarium spp. Phytopathology 92:1160-1166.

Mandeel, Q. and Baker, R. 1991. Mechanisms involved in biological control of Fusarium wilt of cucumber with strains of nonpathogenic Fusarium oxysporum. Phytopathology 81:462469.

Miles, M. R. and Wilcoxson, R. D. 1984. Production of fungal inoculum using a substrate of perlite, cornmeal, and potato dextrose agar. Plant Dis. 68:310.

Mousseaux, M. R., Dumroese, R. K., James, R. L., Wenny, D. L. and Knudsen, G. R. 1998. Efficacy of Trichoderma harzianum as a biological control of Fusarium oxysporum in containergrown Douglas-fir. New Forest. 15:11-21.

Nelson, P. E., Toussoun, T. A. and Marasas, W. F. O. 1983. Fusarium species: an illustrated manual for identification. The Penn- 
sylvania State University Press, University Park, Pennsylvania, USA: 193 pp.

Salerno, M.-I., Gianinazzi, S., Arnould, C. and Gianinazzi-Pearson, V. 2000. Cell interactions between a nonpathogenic Fusarium oxysporum strain and root tissues of Eucalyptus viminalis. J. Gen. Plant Pathol. 70:153-158.

Shishido, M., Miwa, C., Usami, T., Amemiya, Y. and Johnson, K. B. 2005. Biological control efficiency of Fusarium wilt of tomato by nonpathogenic Fusarium oxysporum Fo-B2 in different environments. Phytopathology 95:1072-1080.

Skovgaard, K., Rosendahl, S., O'Donnell, K. and Nirenberg, H. 2003. Fusarium commune is a new species identified by morphological and molecular phylogenetic data. Mycologia 95:630-636.
Spaulding, P. 1914. The damping-off of coniferous seedlings. Phytopathology 4:73-88.

Stewart, J. E., Kim, M.-S., James, R. L., Dumroese, R. K. and Klopfenstein, N. B. 2006. Molecular characterization of Fusarium oxysporum and Fusarium commune isolates from a conifer nursery. Phytopathology 96:1124-1133.

Stewart, J. E., Abdo, Z., Dumroese, R. K., Klopfenstein, N. B. and Kim, M.-S. 2012. Virulence of Fusarium oxysporum and F. commune to Douglas-fir (Pseudotsuga menziesii) seedlings. Forest Pathol. 42:220-228.

Wenny, D. L. and Dumroese, R. K. 1992. A growing regime for container-grown Douglas-fir seedlings. Idaho Forest, Wildlife and Range Experiment Station. Bulletin 49, 8 p. 